\title{
Ritos e risco na prática do vôo livre
}

\author{
Giuliano Gomes de Assis Pimentel ${ }^{*}$
}

\begin{abstract}
Resumo: Vôo livre é uma atividade de aventura na natureza com forte influência da tecnologia aeroespacial e conhecimentos meteorológicos. Este artigo apresenta compreensões sobre o risco no vôo livre e a presença de rituais nessa prática corporal. Para tanto, numa apropriação da pesquisa etnográfica, foi realizado estudo de campo por meio de observação participante, entrevistas e registros de imagens no noroeste do Paraná. Foram identificados três momentos rituais, correspondentes às fases de decolagem, vôo e pouso. Conclui-se que os praticantes transitam entre duas polaridades (segurança e risco), necessitando estabelecer ritos para marcação dessa passagem.
\end{abstract}

Palavras-chave: Risco. Cultura. Vôo livre. Natureza.

\section{INTRODUÇÃO}

A emergência e o desenvolvimento dos esportes aéreos estão relacionados ao anseio ancestral do ser humano em poder voar. Esse sonho pode ser remetido ao mito de Ícaro e Dédalus, quando ambos fogem da prisão por meio do engenhoso uso de asas de cera. Cientistas do porte de Leonardo Da Vinci, desde 1486, já haviam buscado uma forma de voar utilizando a combinação da energia humana e da natureza (JULI, 2005).

Embora o avião tenha significado um avanço nesse ideário, foi a partir dos anos de 1970, com a asa-delta, que o vôo tornou-se livre da necessidade de motor ou combustível, sendo rapidamente assimilado como prática esportiva de lazer. Na atualidade, há 2000 praticantes de asa-delta e 3000 de parapente registrados na Associação Brasileira de Vôo Livre (ABVL), sendo o 'esporte' um dos poucos em que homens e mulheres competem juntos (KOFF; RAAD FILHO, 2005).

\footnotetext{
* Doutor em Educação Física pela Universidade Estadual de Campinas. Docente da Universidade Estadual de Maringá na graduação e no Programa de Pós-Graduação Associado em Educação Física. UEM/UEL, Maringá, PR, Brasil. E-mail: ggapimentel@uem.br
} 
A maioria desses praticantes de vôo livre, pessoas comuns do cotidiano, realiza a atividade como opção de lazer, dado instigante, uma vez que, numa sociedade obcecada pela idéia de atividade física como saúde, essa prática é marcada por riscos à vida. Nesse sentido, a questão do risco é uma dimensão essencial à compreensão dessa prática corporal. Segundo Ramos (2003), como atividade de aventura na natureza, o vôo livre está relacionado a incertezas, interface com o meio selvagem, tendência de risco e desafio, liberdade proporcionada pela aventura e preparação rigorosa da segurança antes e no momento de suas ações práxicas.

Essas características são encontradas em diferentes práticas corporais contemporâneas, as quais representam uma necessidade de encontrar novas formas de sociabilidade e racionalidade, buscando emoções relacionadas à descoberta, particularmente no meio natural. Práticas corporais incluídas nessa tendência são pontuadas por Betrán (2003) como Atividades Físicas de Aventura na Natureza (AFANs). Nelas, a busca por emoções é recorrente entre praticantes, tendo feições mais grandiosas quando envolvem risco.

Esse risco, entretanto, não se refere ao mesmo risco presente nos primeiros aventureiros que, em número bastante reduzido, desbravavam a natureza, submetendo-se a grande esforço físico no enfrentamento de diferentes ameaças, tais como doenças infecto-contagiosas, acidentes e fome. $\mathrm{Na}$ atualidade, o risco pode ser produzido eminentemente com finalidade de lazer. E, embora o senso comum veja essas práticas de aventura como instáveis e perigosas, existe racionalização dos riscos (risco controlado) por meio de técnicas e equipamentos de segurança. No vôo livre, por exemplo, checa-se repetidamente o trinômio piloto-equipamento-condição meteorológica. Não há decolagem caso algum desses parâmetros não esteja confiável.

Por outro lado, o entendimento de risco é fruto da própria modernidade, cuja fase atual de desenvolvimento experimenta, segundo Giddens (2005, p. 71), novos contornos. O processo de globalização tornou os riscos "[...] incalculáveis na origem e indeterminados nas suas conseqüências [...]", passando o enfoque do individual para o coletivo. Nesse sentido, embora exista uma busca pelo controle, a sociedade globalizada muda rapidamente, impondo incertezas e tornando

Movimento, Porto Alegre, v. 14, n. 03, p. 13-32, setembro/dezembro de 2008. 
arriscadas decisões de todos os níveis. É nesse cenário que as AFANs multiplicam-se.

É premissa do presente texto que, não obstante sua natureza racionalista e homogeneizante, a modernidade globalizada acabou por desencadear reações locais e tidas como não-racionais (como o misticismo, a sensibilidade e a intuição). Nesse sentido, por meio de um olhar sociocultural sobre as AFANs, apresenta-se a contraditória conciliação entre elementos racionais e não-racionais na vivência dessas práticas corporais.

As sociedades humanas tradicionais, quando sujeitas aos riscos externos, faziam uso de ritos preparatórios às ameaças provenientes da natureza. Mesmo a tecnologia fornecendo elementos mais objetivos para a administração dos riscos produzidos pela própria intervenção humana no meio natural, o vôo livre apresenta rituais de transição entre o ambiente 'seguro' do cotidiano e o campo de aventuras, no qual se procura deliberadamente enfrentar riscos como opção de lazer. Na interface com posições teóricas pertinentes à questão da aventura, o foco deste trabalho é descrever a ocorrência desse fenômeno em um contexto particular e compreender significados a ele atribuídos.

\section{Aspectos metodológicos}

Ao descrever essa trama, buscou-se a indicação de Maffesoli (2001) sobre adotar uma sensibilidade teórica frente à realidade, sempre contraditorial. Portanto, não cabe simplificá-la, pela imposição da verdade única, ou esgotar o mistério da vida com explicações causais, mas trata-se de participar dela, apontando seus problemas, aporias e suas contradições. Destarte, investe-se na descrição da vida e sua compreensão, sem a pressa de querer rotulá-la. Para o autor, é necessário colocar-se no lugar daquilo que se observa com empatia, como uma possibilidade de melhor compreender as representações dos sujeitos.

Para tanto, realizou-se trabalho de campo na perspectiva etnográfica. Como lembra Stigger (2002), a etnografia preconiza a

Movimento, Porto Alegre, v. 14, n. 03, p. 13-32, setembro/dezembro de 2008. 
análise em profundidade, sem visar a generalizações, mas, pelo contrário, permite desconstruir os discursos baseados na generalização. Fez-se uso do caderno de campo e da entrevista como técnicas principais de coleta. Houve apoio de registros fotográficos e filmagem em alguns momentos da vivência.

Considerando os vários tipos de observação dos participantes que permitem a produção de uma descrição densa, registrada no caderno de campo, optou-se por revelar aos atores pesquisados a presença do pesquisador, estando este presente, por exemplo, durante a alimentação, hospedagem, transporte, descanso, reuniões, informações, montagem de equipamentos, resgate e momentos frugais da atividade.

As entrevistas compuseram um material importante no cruzamento de dados. Elas permitiram acessar e compreender, utilizando as palavras de Minayo (1999, p. 134) "[...] os valores culturais e as representações de determinado grupo sobre temas específicos". Todos os entrevistados foram escolhidos intencionalmente. A seleção dos mesmos teve os seguintes critérios: aceitar participar do estudo, ser piloto recreativo ${ }^{1}$ e voar (exclusivamente ou não) na pista de vôo de Terra Rica, região noroeste do Paraná. Nessa escolha, ainda pesou: (a) se já haviam sido identificados desde o início da pesquisa; (b) indicação por parte de outros informantes; (c) tempo de experiência; (d) acessibilidade. Embora a descrição etnográfica tenha investido em um número maior de pessoas, foram gravadas entrevistas com dezesseis pilotos: nove de asa-delta e sete de parapente. Ao verificar a saturação dos dados, à medida que as respostas iam reiterando-se, a coleta foi encerrada.

A análise cruzou a entrevista transcrita e as descrições de campo sobre cada pessoa ou grupo. Posteriormente, com base em pré-categorias (risco, aventura, corpo, decolagem, vôo, pouso, saúde, entre outras), as representações individuais foram cruzadas em busca de

\footnotetext{
${ }^{1}$ Por praticante recreativo ou esportivo entende-se, a partir de Semenoff (1998), aquele piloto com mais de um ano de vôo, que voa aos finais de semana, usando asa ou parapente nível II, conforme a classificação da Associação Alemã de Vôo Livre para o tipo intermediário. Essas pessoas interessaram ao estudo, porque já assumiram a prática dessas AFAN's no seu estilo de vida sem, entretanto, descaracterizar essa prática como opção eminentemente de lazer. No fim, foram incluídos participantes entre os níveis I e III, até porque essas classificações nem sempre refletem a realidade do piloto.
}

Movimento, Porto Alegre, v. 14, n. 03, p. 13-32, setembro/dezembro de 2008. 
similaridades e contradições. Buscou-se, evitando tomar como evidentes os significados do discurso, a relação entre representações e ações, considerando a interpenetração entre objetividade e subjetividade e entre discurso e base técnica. Os participantes assinaram termo de consentimento, permitindo o uso e divulgação de seus depoimentos. $^{2}$

\section{SOBRE OS RITOS NO VÔO}

O vôo livre pode ser realizado por meio de asa-delta ou, mais recentemente, pára-quedas apropriados, denominados parapente (em francês) ou paraglider (em inglês). Cada um desses tipos de "asa" envolve aprendizado próprio, dadas as especificidades técnicas. Porém, é possível identificar ações comuns aos dois modos de vôo, sendo elas as evidências primeiras de uma rede de gestos - ambiguamente objetivos e subjetivos. A efetivação consciente das tarefas mínimas (comuns a todos os pilotos) exige formação, que pode, em geral, durar de quatro dias a seis meses.

Em síntese, um piloto formado, ao chegar ao local de decolagem, deve observar as condições atmosféricas. Ao considerá-las adequadas, prepara o material, verificando sua segurança. De costas (parapente) ou de frente (asa-delta) para o vento, buscará uma direção do vento que infle sua vela por igual. Com as linhas bem esticadas, levantar a asa do chão de forma simétrica, recuando um ou dois passos. Correr, até sentir que a asa decolou, quando, então, estará totalmente introduzido em seu equipamento e fará manobras de direção. Um iniciante fará um vôo direto para o campo de pouso (vôo prego), enquanto pilotos experientes, conforme sua interação com as condições (vento e térmica), ainda podem voar beirando a montanha (vôo lift) ou tentar ganhar altitude se enroscando nas térmicas. O pouso é feito por meio de visualização do local escolhido, movimentos de aproximação com diminuição da velocidade (freio gradativo) até o pouso, contra o vento, quando é dado o stall (freio completo).

${ }^{2}$ Registro 226/04, parecer 019/05, em conformidade com a Resolução 196/96 do CNS/MS.

Movimento, Porto Alegre, v. 14, n. 03, p. 13-32, setembro/dezembro de 2008. 
Esse trajeto pode ser sintetizado em três níveis de interação com o risco: decolagem, vôo e aterrissagem. Abdalad (2005), em estudo sobre os significados do vôo livre para as mulheres, chegou a subdividir seu texto de mestrado em consonância às fases do vôo que, para ela, seriam quatro: (a) preparação do salto; (b) salto; (c) deslizamento pelos ares; e (d) pouso. ${ }^{3}$

Analogamente, tais estágios podem ser remetidos à tríplice estrutura diacrônica do ritual: o postulante é separado do profano; é apartado da vida secular; retorna, por fim, à vida normal. Em termos estruturais, ou seja, em relação à estrutura social, os termos "separação", "margem" e "reagregação" preconizam como os rituais podem fornecer uma visão alternativa da realidade social. Assim, esses termos podem ser usados, respectivamente, quando o corpo social se separa do cotidiano, vive à margem dele (indicando que a estrutura está periférica, mas nunca excluída) e retorna à estrutura social. Já quando o rito é referido quanto às transições espaciais, como entrar-permanecer-retornar da mata, do mar, do ar ou do solo sagrado, são usados os termos "pré-liminar", "liminar" e "pósliminar" (TURNER, 1974).

Percebe-se que o núcleo revolucionário do rito de passagem ocorre em adentrar nesse limiar ou margem. Adjunta Abdalad (2005), que, uma vez dentro, a percepção do interior é de transcendência do profano e ingresso no sagrado, sendo função dos ritos acompanhar a passagem desse limiar. No caso de esportes aéreos, a autora credita aos pequenos gestos (organizar o material, observar os fenômenos meteorológicos ou se encaixar defronte ao vento) o papel de rituais que conduzem e aproximam o piloto do céu, preparando-o para um salto no vazio em direção às nuvens.

No caso do vôo, a analogia com rito de passagem é bastante fértil, podendo dar-se nos dois sentidos aludidos por Turner (1974). Em relação à tríade separação-margem-reagregação, muito análoga

\footnotetext{
${ }^{3}$ Uniram-se aqui as duas primeiras fases, considerando que ambas se referem a um mesmo estágio ritualístico (pré-liminar), relacionado à premência da passagem para outra dimensão espacial (da terra para o ar). A divisão do vôo em momentos é limitada para a compreensão do fenômeno em sua idiossincrasia. O vôo livre é uma totalidade, porque, obviamente, não existe pouso sem vôo, nem vôo que não seja precedido de decolagem. Mas a leitura nativa sobre os estágios do vôo permite uma analogia fértil à percepção de emoções predominantes no interior de cada momento ritual.
}

Movimento, Porto Alegre, v. 14, n. 03, p. 13-32, setembro/dezembro de 2008. 
à dinâmica do enraizamento dinâmico, o piloto se liberta de sua residência e posição social, experimenta intensamente outra socialidade e, depois, retorna para a segurança de seu cotidiano. No segundo aspecto, mais relacionado ao tempo e ao espaço, decolar representa separar-se da vida terrena, sendo inserido noutra dimensão liminar enquanto desliza pelo ar, com retorno ao solo na aterrissagem.

Sobre esse aspecto, uma das possibilidades de entendimento é lançada por Maluf (2005), para quem o rito permite uma dupla interface de contato. Primeiro, entre pensamentos conscientes e pensamentos inconscientes, contribuindo à superação dos receios. Segundo, entre pessoas com status diferentes, a partir da repetição dos mesmos gestos e do compartilhamento de uma mesma experiência. Dada a influência da ritualização sobre a conduta dos participantes, a autora assevera uma dimensão intencional do rito.

Já para Maffesoli (1998), o ritual é algo predominantemente não funcional, sendo admissível apenas, e tendo como única função: "[...] reafirmar o sentimento que um dado grupo tem de si mesmo". Aquilo que chama atenção nas atividades ritualísticas ordinárias da atualidade, além da capacidade em aproximar a racionalidade sensível e a racionalidade instrumental, é sua expressão como um retorno aos laços sociais. "Através da multiplicidade dos gestos rotineiros ou quotidianos, o ritual lembra à comunidade que ela 'é um corpo'. Sem a necessidade de verbalizar isto, o ritual serve de anamnese à solidariedade" (MAFFESOLI, 1998, p. 25).

Maffesoli (1985) considera que os rituais são carregados de ludismo, sendo os primeiros e principais indícios de passagem da natureza à cultura. $\mathrm{O}$ autor ainda complementa que, embora visem a domesticar o que é estranho, e estando passível de conflitos, os rituais acabam permitindo uma integração entre elementos cotidianos e extraordinários.

Em linhas bem próximas, DaMatta (1983) adota o rito como uma dramatização responsável por atender a necessidades primárias, transformando-as em coisas sociais. O mundo ritual seria relativo ao cotidiano, estando qualquer ação sujeita à ritualização. Por isso, atos banais, a exemplo de observar um urubu no céu ou subir um morro, podem ser reinvestidos de um alto significado e, ordenados numa

Movimento, Porto Alegre, v. 14, n. 03, p. 13-32, setembro/dezembro de 2008. 
seqüência, compor um rito. Esse momento tornado extraordinário permite colocar em foco um aspecto da realidade, deslocá-lo e recriá-lo.

Dadas essas aproximações teóricas, este texto parte do entendimento da dimensão ritual do vôo livre, cujas fases dão suporte ao enfrentamento do risco deliberadamente buscado como opção de lazer.

\title{
4 RituAL DE ENTRADA: A DECOLAGEM
}

Todo ritual de passagem é precedido por incertezas, visto representar o deslocamento de um mundo conhecido para experimentar outra realidade (a margem ou limiar). No vôo, a transição ocorre entre terra e ar. Sobre essa fase, há relatos de enfrentamento pessoal do medo e de reações corporais bem familiares: aumento dos batimentos do coração; falta de firmeza nas pernas (tremem); dilatação da pupila; sudorese e boca seca.

\begin{abstract}
Primeiro lugar lutar contra o medo, né?! Porque o medo é instintivo. Faz o ser humano permanecer vivo. É uma luta mental contra uma vozinha na sua cabeça que diz "o que você está fazendo aqui? Você está maluco? Isso aqui é um estresse muito. Você está brincando com a vida?" Então, é vencer o medo. [...] Nesse momento é o maior choque de adrenalina em que você está a segundos para decolar. A saliva some da boca. Minha boca seca. (PILOTO DE ASADELTA E PARAPENTE, adulto, residente em São Paulo-SP).
\end{abstract}

Conforme os depoimentos dos participantes, esse fragmento de tempo, quando o piloto "tem que decidir", sintetiza todo o conhecimento técnico acumulado, os receios, medos e expectativas não só de quem decola, mas também dos colegas presentes. O termo "adrena" é utilizado pelos praticantes para se referirem ao estresse agudo pertinente no momento precedente ao ingresso no espaço aéreo. As falas são ambíguas em relação a esse sentimento, pois ele tanto atrapalharia as tomadas de decisão quanto, também, seria uma tensão necessária e desejada.

Para Le Breton (2006, p. 104), o estresse aparece como uma tentativa de equilibrar as capacidades do aventureiro e o terreno sobre o qual ele exerce sua força: “[...] longe de ser sempre uma

Movimento, Porto Alegre, v. 14, n. 03, p. 13-32, setembro/dezembro de 2008. 
situação da qual se deve fugir, o estresse torna-se aqui, em circunstâncias desejadas pelo indivíduo, objeto de um desejo apaixonado destinado a oferecer um sabor crescente à existência". Nesse sentido, o termo adrenalina, na linguagem dos praticantes, ainda segundo o autor, corresponde ao que denomina-se de estresse, porém, é entendido como algo buscado, uma forma de intensificar o sentimento de estar vivo.

O ponto de equilíbrio viria quando a entrega e o controle se complementam. Como diz um dos pilotos de asa-delta, residente em Curitiba-PR:

\begin{abstract}
Você se coloca na mão da mãe natureza. Como uma folha levada com o vento, só que com certo controle e respeito de fazer a brincadeira numa hora certa e num tempo bom. Porque o perigo do vôo livre é você decolar na hora errada ou com muito ou pouco vento. Então existe uma margem de segurança onde você pode brincar sem problema[...].
\end{abstract}

Diante da imponderabilidade que marca a prática, sendo a natureza um elemento caótico, o ritual visa a ratificar esse 'mais-controle', transformando o acaso em um dado social passível de ser absorvido pela dramatização. Elementos como observar o céu, montar o equipamento na mesma seqüência, meditar - sentado ou deitado - em contato com a terra e o movimento ficar se encaixando na asa, ou inflando o glider - até se chegar a um nível que agrade ao piloto -, mostram a presença de uma sensibilidade intuitiva em curso.

Interessante notar que esses gestos mencionados possuem uma carga simbólica de organização dessa interação do microcosmo, que é o piloto, com o macrocosmo. Tudo precisa ser feito 'daquela forma', a ponto de certos pilotos ficarem irrequietos e não voarem enquanto sentirem falta do cumprimento de algum gesto habitual. Essa percepção subjetiva pode se referir a detalhes, como: o barulho da vela está diferente; falta uma fita do Senhor do Bom Fim amarrada ao equipamento; uma empunhadura incômoda; não sentir o vento no rosto e na asa. O 'líder' do grupo investigado reforçava reiteradamente que o piloto deve sentir a presença do vento certo, quando a asa "quer voar", pois "forçar uma situação" ou agir distraidamente na preparação para o vôo geralmente redunda em acidentes.

Movimento, Porto Alegre, v. 14, n. 03, p. 13-32, setembro/dezembro de 2008. 
Concluindo, a decolagem é precedida pela tensão característica da separação do indivíduo de seu meio habitual, que pode se dar desde a saída do piloto de sua residência. O próprio ato de jantar, dormir, despertar e abrir a janela de casa para observar as condições do tempo já não se dá mais de forma ordinária como nos dias corriqueiros. Em geral, vencida a 'adrena' inicial, os relatos (entre sujeitos da pesquisa e na literatura) enfatizam outras sensações, associadas ao prazer, tranqüilidade, êxtase místico, paz, liberdade, surpresa, solidão diante da imensidão dos espaços vazios. Sobre essa nova composição do corpo com a prática, desvela-se o segundo momento ritual.

\section{RITUAL DE SUSPENSÃO: O Vôo}

A fase limiar, no vôo livre, é pontuada pela efetivação da decolagem, quando o piloto deixa de tocar o solo, ganhando vôo. A partir dessa etapa, conforme a tipologia das fases rituais, o indivíduo está preparado para ritos de aliança ou agregação ao novo mundo. Para tanto, a liminaridade é o período de supressão das diferenças e marcadores sociais, os quais são realocados (em outros termos) no período pós-liminar (GENNEP, 1977).

É próprio do estágio liminar o contato com outra dimensão e a suspensão transitória da realidade instituída. Logo, o elemento gerador dessas percepções é o estado de suspensão, tomado aqui em dois sentidos: (a) o corpo suspenso no ar pela asa/glider e (b) a suspensão temporária de normas e preocupações da vida cotidiana.

Em complemento, esse é um momento intenso em relação às percepções, pois o corpo capta muitas informações do meio concomitantemente à experimentação de algumas emoções absorventes. Em suma, os elementos rituais promovem a suspensão do tempo contínuo e o predomínio do tempo cíclico (início, meio e fim ritual). Voar é o clímax do ritual.

Como já tratado por Abdalad (2005), o rito no vôo está associado a tentativas de suprimir a rotina do cotidiano, estabelecimento - imaginado - de relações mais cooperativas com o meio natural e à valorização do momento presente. Porém, o principal aspecto no rito

Movimento, Porto Alegre, v. 14, n. 03, p. 13-32, setembro/dezembro de 2008. 
de passagem de uma pessoa da terra para a nuvem, "elemento onírico transformador", é a conquista de uma "nova dimensão e sentir-se tão livre quanto estar na sua casa, num lugar onde desfruta de intimidade" (ABDALAD, 2005, p. 109).

Ao que parece, essa percepção de liberdade, relatada por diferentes pilotos em Terra Rica, reitera o aspecto da transição entre pólos, quando as sensações afetam um corpo que está em sustentação no ar. O estar flutuando e deslizando, suspenso no espaço, implica, sobretudo, uma vivência particular de corporeidade.

Nas falas, o estado de suspensão do corpo no espaço (aparentemente ilimitado) é remetido à 'liberdade de' disposições institucionais e preocupações cotidianas e 'liberdade para', mais especificamente em relação ao rito, incorporar certas referências mitológicas:

Ser super-homem. Voar de asa delta é um dos sonhos que me realizou em tudo: sensação de liberdade, de altura e, principalmente, você poder estar sozinho nas alturas do universo, podendo observar tudo do alto e você falar - Eu posso! Eu sou voador. Eu sou uma águia. Então é isso: ser uma águia, sendo um ser humano. (PILOTO DE ASA-DELTA, negro, de origem rural e, atualmente, trabalhador assalariado residente em Curitiba-PR)

Uma liberdade de você sentir que está de acordo com a natureza e poder ir para o lado que você quiser. Quase como um pássaro, mas pássaro bate asa, a gente não. Mas você consegue estar em sintonia com a natureza, que eu acho que é bem importante. É bem legal isso aí e você estar em liberdade, voando; ver em que direção você quer ir. (PILOTO DE ASADELTA, nipônico, 'médio empresário', residente em Maringá-PR)

A liberdade, referida quase unanimemente, parece tanto dizer respeito ao indivíduo livrando-se - ainda que momentaneamente - de rótulos impostos pela sociedade sobre como pensar e como viver o corpo, como, também, ao aspecto catártico e compensatório do êxtase.

É nesse tocante que a fase de transição no rito tem como eixo a noção de suspensão momentânea da estrutura social dominante (seja para confirmá-la ou antever sua modificação). Conforme Turner

Movimento, Porto Alegre, v. 14, n. 03, p. 13-32, setembro/dezembro de 2008. 
(1974), na liminaridade, as experiências místicas ou de desvio, comuns a determinado grupo, permitem que certos significados se movam e, portanto, possa haver resignificação. Entretanto, não há garantias de interferência para outras esferas da vida, porque, cognitivamente, a vivência do novo mundo paradoxalmente acaba realçando a regularidade do cotidiano (TURNER, 1974).

Embora intensa para todos, a forma como essa fase se expressa é muito particular e nem sempre se percebe abertura suficiente dos sujeitos para a mudança de status que o rito de passagem (voar) potencialmente enseja. Alguns consideram o momento de suspensão como o pico da adrenalina, enquanto um grupo mais experiente associa às questões espirituais.

Prepondera, no estágio liminar, o estudo das sutilezas. A primeira dificuldade para imergir teoricamente nesse fenômeno é a incapacidade da linguagem enquadrar algo que, por vezes, ultrapassa a compreensão do praticante. Além disso, é comum ouvir dos pilotos que é "inexplicável", "só voando para saber [...]". Os signos em curso nessa fase dizem respeito a uma lógica não formalizada pela linguagem verbal, contribuindo à polissemia.

\section{RITUAL DE REINGRESSO À NORMALIDADE: A ATERRISSAGEM}

O momento da aterrissagem é considerado por muitos pilotos como um novo momento de tensão, equivalente à decolagem. Se, para sair do morro e ingressar no ar, o piloto vive a apreensão da troca de ambiente, o pouso significa o retorno ao solo, com os diferentes riscos associados a um pouso feito em local impróprio (arborizar) ou de forma desequilibrada, tombando na aterrissagem (crechar).

O tombo no pouso é motivo de gozação entre os pilotos, mas, na verdade, trata-se de um procedimento muito complexo. A má aproximação e o desequilíbrio são associados a uma falha na composição do corpo com o equipamento, num momento já de cansaço. Além do cálculo equivocado da distância, o piloto pode não nivelar adequadamente os lados da asa, fazendo com que caia para frente ou lateralmente. As térmicas (ar quente) desprendidas do solo são citadas como outro aspecto que torna o pouso um momento tenso.

Movimento, Porto Alegre, v. 14, n. 03, p. 13-32, setembro/dezembro de 2008. 
Ao se aproximar do solo, a asa é inflada para o alto, afastando o piloto do local mais adequado para o pouso.

Superar esses desafios, para os pilotos, resulta num contínum tensão-distensão. Após o pouso, muitos aproveitam para meditar, contemplar, confraternizar-se ou, simplesmente, experimentar um alívio por haver superado os desafios. Em alguns casos, o arrebatamento do êxtase perdura no pouso e vem acrescido da percepção de bemestar e relaxamento. Enfim, como pondera um piloto de parapente, vindo de Santa Catarina, o momento do pouso encerra um ciclo: "O estado de pouso já é outro caso. Aí já começa a voltar à terra. Aí você está voltando ao estado físico".

Como momento síntese, tal fase de re-agregação pós-liminar (aterrissagem e pouso) evoca nos pilotos atitudes associativas no sentido de compartilhar conhecimentos adquiridos e reminiscências das emoções percebidas. A observação permitiu detectar que, após a asa ser estacionada, cada experiência é relatada aos colegas de forma efusiva e detalhada. Poucas horas depois, seja nas entrevistas ou nas conversas dos bares, as descrições tornam-se 'frias'.

O ambiente do pouso, nesse sentido, é um território privilegiado, para que os segredos dos grupos sejam alimentados. Ali ocorre avaliação da decolagem, do vôo e do pouso, é desmontada a asa, os pilotos hidratam-se, são feitos ajustes para a próxima decolagem ou, quando já não é possível mais voar, reúnem-se em pequenas tribos para um intercâmbio mais detalhado até que o resgate chegue ou haja ânimo para ir embora. Também foi comum ver algum piloto momentaneamente afastado dos demais, devido a estar refletindo sobre aspectos relevantes do vôo ou simplesmente por estar exausto.

Para compreender, numa visão menos impositiva, qual o significado de todo o voar ou, enfim, o que ganhou ou adquiriu o voador ao chegar ao pouso, faz-se necessário perguntar se o objetivo do piloto é chegar ao pouso. Ao contrário do nadador olímpico que deseja atravessar a piscina no menor tempo, o desejo da maioria dos pilotos é ficar o maior tempo em permanência no ar, tal como a criança que brinca na piscina, pelo prazer de estar na água. Ninguém voa exclusivamente para chegar ao local de pouso, embora esse retorno pós-liminar seja almejado.

Movimento, Porto Alegre, v. 14, n. 03, p. 13-32, setembro/dezembro de 2008. 
Bem em consonância com a exortação de Sant'ana (2001) sobre a ética do momento nos esportes na natureza, voar coincide ato e finalidade. Voar é o próprio fim. Pousar é conseqüência da impossibilidade ou da falta de desejo em permanecer mais tempo voando. E o que se faz e se sente durante o pouso têm, sobretudo, a ver com as emoções construídas nessa prática. A percepção de elementos rituais nessa atividade lúdica, o vôo, realça o aspecto de improdutividade do jogo ao sistema, algo que - sobretudo - é consumido em si mesmo, sem garantias de projeção sobre outras esferas da vida.

Tomando como mote o 'gastar-se em si mesmo' dessas práticas, uma inferência possível das mesmas, mesmo entendendo nelas as contradições e desigualdades da sociedade capitalista, relaciona-se à dimensão ociosa (no sentido grego de scholé, um não-fazer criativo) do vôo livre. Maffesoli (1997) inverte a lógica dominante e nos faz pensar se não seriam as coisas inúteis as mais significativas na vida. Para ele, quando algo tem seu valor no critério da produtividade acaba por tornar-se obsoleta, pois tudo aquilo sem um pouco de supérfluo acaba, perversamente, decretado a um dia ser obsoleto.

\section{CONSIDERAÇÕES FINAIS}

Neste artigo, discutiu-se como é construída, no plano sociocultural, a percepção de voar e como as sensações nos momentos ritualisticamente bem delineados de "decolagem", "vôo" e "aterrissagem" podem favorecer ou ser decorrentes de determinadas representações sociais. Sobre a decolagem, emergiram questões como o medo, o significado de estar "adrenado", o estresse em relação à saída da rampa e como ele se articula ao estresse cotidiano. Em relação ao vôo, privilegiou-se a noção de suspensão ao analisar o êxtase, o diálogo com a natureza e as emoções e sensações atribuídas a cada tipo de vôo. Aspectos como o medo das quedas, o estado de relaxamento e a necessidade de estar só e com os outros após o vôo foram pontuadas na apreciação sobre o momento de pouso e desmontagem do equipamento.

Embora experiências corporais subjetivas e íntimas, as transições liminares não estão isoladas no indivíduo. Estão inseridas em

Movimento, Porto Alegre, v. 14, n. 03, p. 13-32, setembro/dezembro de 2008. 
códigos ético-estéticos de uma determinada socialidade subterrânea que se desenraiza e, de ciclo em ciclo, provoca uma suspensão momentânea dos padrões institucionais e das preocupações cotidianas. Então, dada a pertinência dessa questão, encerra-se este texto trazendo algumas reflexões teóricas de âmbito mais geral, as quais foram despertadas pela particularidade do estudo.

Para Mafessoli (1998), um dos elementos marcantes dessas novas comunidades é o desenvolvimento do ritual. Este não seria voltado para um fim, mas apenas reafirmaria os sentimentos postos em jogo no ritual, especialmente sobre a potência da sociabilidade. Enfim, o ritual exprimiria, sobretudo, sua condição cíclica, repetitiva, de retorno a si mesmo. Essa característica do rito na socialidade contemporânea permitiria um sentimento de segurança, arremata o autor.

Segurança essa - dentro da lógica do enraizamento dinâmico em contraste e, ao mesmo tempo, em composição com a busca pela liberdade nas práticas de aventura. Para Maffesoli (2001, p. 120), a liberdade nômade é diferente daquela pregada pela burguesia, porque se baseia na relação entre "[...] politeísmo de valores, paganismo cotidiano e valorização de um presente do qual convém viver todas as potencialidades".

Maffesoli (1997) considera que a primazia da eficácia nas sociedades modernas contribuiu para o decréscimo gradativo do sentimento coletivo. Essa práxis enfatiza o futuro, como se tudo tivesse um objetivo e apenas faltasse encontrar os meios. Como já é comum em suas análises, o autor lembra que toda luz lançada sobre o futuro aumenta o lado sombrio do presente. A institucionalização e a racionalização da sociedade moderna levaram à pasteurização da vida cotidiana. Para ele, esse foi um dos motivos para que a sociedade ficasse cada vez mais anômala.

A crise desse modelo acarretou o ressurgimento de elementos arcaicos que souberam aproveitar as inovações tecnológicas para fomentar a socialidade não-institucional. Nesse sentido, aparece (embora com mais freqüência entre os jovens) outra perspectiva, a que sobrevive do eterno presente. O objetivo não é tão importante quanto o prazer do ato ou do momento. Para Maffesoli (1997, p. 174),

Movimento, Porto Alegre, v. 14, n. 03, p. 13-32, setembro/dezembro de 2008. 
essa perspectiva de "[...] parar o tempo a fim de gozar as múltiplas pequenas ocasiões ou ocorrências sociais ou pessoais [...]" não significa nenhum narcisismo. Mas uma decisão de quem não acredita mais na promessa de equilíbrio numa sociedade futura.

Como conseqüência, muitas socialidades estão vivendo o aqui e agora, "[...] ao qual se adaptam de maneira 'contraditorial', isto é, sem serem 'superados' os diversos elementos heterogêneos do cotidiano [...]", levando tais grupos a "[...] aceitar os dias de sorte e os dias nefastos" como o tipo de equilíbrio possível (MAFFESOLI, 1997, p. 175). A aventura acabou por ser umas das formas contraditórias de encarar essas transformações no modelo de sociedade e na identidade das pessoas. Para muitos, "[...] a continuidade da existência é feita de múltiplos desvios, de bons momentos particulares, de acontecimentos efêmeros, da mistura íntima de perigo e intensidade" (MAFFESOLI, 1988, p. 116).

Tal nomadismo hedonista veio acompanhado de novas formas de encarar a aventura e a consciência do risco, típica de uma fase reflexiva da modernidade. Numa sociedade que se vê diante da desestruturação do capital social, "[...] as novas aventuras propiciam alguma forma de enraizamento numa sociedade pautada pelos processos de individualização e de destradicionalização". Essa busca de sentido à existência talvez seja "[...] o aspecto mais central para a compreensão da relação entre risco e aventura na modernidade reflexiva" (SPINK, 2008, p. 07).

Quando se observa o vôo livre no ambíguo terreno das atividades de aventura, é preciso, portanto, reconhecer que essa prática está vazada pela hibridação entre aspectos racionais e sensíveis (uma racionalidade outra). Segundo os pilotos experientes, o trinômio pilotocondição-equipamento é a razão de segurança (ou administração dos riscos) dessa prática corporal. Entretanto, devido a persistirem elementos fora do controle e do planejamento, não é possível racionalizar todas as ações frente aos riscos (reais e imaginados) do vôo. Com o equipamento sendo responsável, dizem, por apenas $1 \%$ dos acidentes, o elemento humano revela-se tão impreciso quanto a natureza com a qual deseja dialogar nos céus.

Movimento, Porto Alegre, v. 14, n. 03, p. 13-32, setembro/dezembro de 2008. 
A percepção humana do risco no vôo livre leva pilotos e pilotas a considerarem a imponderabilidade e buscar, para além dos apetrechos e técnicas, outras regularidades. Outrora, a coesão comunitária ou a noção de destino apaziguavam a inquietação frente ao desconhecido. Já na modernidade reflexiva, cujo signo mais evidente seria o risco, apostou-se na competência tecnológica e na individualidade. Sabese que isso só fez aumentar o sentimento de inquietação frente às múltiplas possibilidades intervenientes em cada cenário.

Neste estudo, o ritual, construto cultural de forte eficácia simbólica, em tese, se colocou como a mediação efetiva com a fatalidade. Todavia, não se chegou à conciliação possível entre os pólos, senão uma tensão complementar. Isso significa negar qualquer representação - simplista - de equilíbrio entre a dimensão racional (a meteorologia, os gestos técnicos, a tecnologia de vôo, os equipamentos de segurança) e a sensível (a espiritualidade, a pulsão gregária, os rituais) por meio dessas práticas na natureza. A polaridade, porém, lembrando a fase clímax do rito, encontra sua suspensão temporária quando, deliberadamente, se coloca a vida em jogo, haja vista ser impensável alcançar essa condição sem que a totalidade se manifeste na experiência humana.

Movimento, Porto Alegre, v. 14, n. 03, p. 13-32, setembro/dezembro de 2008. 


\title{
30 Artigos Orignais Giuliano Gomes de Assis Pimentel
}

\begin{abstract}
Rites and risk in the hang-gliding practice
Abstracts: Hand Gliding is an adventurous activity in nature whose feature is flying by using the aerospace technology and meteorological knowledge. The objective was to understand the meanings given to risk from hang gliding, and the presence of rituals in that corporal practice. To that, appropriating ethnographic research, a study was performed by observing the people and interviewing them and also through images recorded in northwest of the Paraná. The study analyzed the three phases of the ritual: takeoff, flight and landing. Concluding, those people transit between these two ambits (safety and risk), needing to establish rites for demarcation of that transition.

Keywords: Risk. Culture. Hand Gliding. Nature.
\end{abstract}

Ritos y riesgo en la práctica del vuelo libre.

Resumen: El vuelo libre es una actividad de aventurera en naturaleza, usando la tecnología aerospacial y el conocimiento meteorológico. Esto artículo muestra significados acerca de los riesgos en vuelo libre, $y$, también, la presencia de rituales en esa práctica corporal. A eso, en una aproximación con la etnografía, se ejecuto un estudio gravando imágenes, observando personas y entrevistándolas, en noroeste del Paraná. El estudio analizó las tres fases del ritual: el despegue, vuelo y desembarco. Concluyendo, las personas se alternan entre ámbitos (seguridad y riesgo), necesitando establecer aquellos ritos para demarcaren la transición entre polaridades.

Palabras-clave: Riesgo. Cultura. Vuelo libre. Naturaleza.

\section{REFERÊNCIAS}

ABDALAD, Luciana S. Mulheres e vôo livre: o universo feminino nos esportes de aventura e risco. Niterói: Nitpress, 2005.

BETRÁN, Javier O. Rumo a um novo conceito de ócio ativo e turismo na Espanha: as atividades físicas de aventura na natureza. In: BRUHNS, Heloisa T.; MARINHO, Alcyane (Org.). Turismo, lazer e natureza. São Paulo: Manole, 2003. p. 157-202.

DA MATTA, Roberto. Carnavais, malandros e heróis: para uma sociologia do dilema brasileiro. 4. ed. Rio de Janeiro: Zahar, 1983.

Movimento, Porto Alegre, v. 14, n. 03, p. 13-32, setembro/dezembro de 2008. 
GENNEP, Arnold Van. Os ritos de passagem: estudo sistemático dos ritos da porta e da soleira, da hospitalidade, da adoção, gravidez e parto, nascimento, infância, puberdade, iniciação, ordenação, coroação, noivado, casamento, funerais, estações, etc. Petrópolis: Vozes, 1977.

GIDDENS, Anthony. Sociologia. 6. ed. Porto Alegre: Artmed, 2005.

JULI, Ramos B. Aeronáutica vinciana. Apunts: Educación Física y Deportes. Barcelona, n. 80, p. 75-76, 2005

KOFF, José; RAAD FILHO, Nader C. Vôo livre. In: DA COSTA, Lamartine P. (Ed.). Atlas do esporte no Brasil. Rio de Janeiro: Shape, 2005. p. 479-480.

LE BRETON, David. Risco e lazer na natureza. In: BRUHNS, Heloisa T; MARINHO, Alcyane (Org.). Turismo, lazer e natureza. São Paulo: Manole, 2003. p. 94-117.

MAFFESOLI, Michel. Sobre o nomadismo: vagabundagens pós-modernas. Rio de Janeiro: Record, 2001.

Os tempos das tribos: o declínio do individualismo nas sociedades de massa. 2. ed. Rio de Janeiro: Forense, 1998.

A transfiguração do político: a tribalização do mundo. 2. ed. Porto Alegre: Sulina, 1997.

O conhecimento comum. São Paulo: Brasiliense, 1988.

A sombra de Dionísio: contribuição a uma sociologia da orgia. Rio de Janeiro: Graal, 1985.

MALUF, Sônia W. Mitos coletivos, narrativas pessoais: cura ritual, trabalho terapêutico e emergência do sujeito nas culturas da "Nova Era". Mana, Rio de Janeiro, v. 11, n. 2, p. 499-528, 2005.

MINAYO, Maria C. S. O desafio do conhecimento: pesquisa qualitativa em saúde. 6. ed. São Paulo: Hucitec, 1999.

RAMOS, José Ricardo da Silva. Esporte de aventura: um olhar praxiológico a partir dos praticantes de vôo livre da cidade de Niterói. In: Praxiologia motriz no Brasil. Niterói: L. A. Erthal: Faculdades Integradas Maria Tereza, 2003. p. 71-82.

SANTANA, Denise B. Corpos de passagem: ensaios sobre a subjetividade contemporânea. São Paulo: Estação Liberdade, 2001.

SEMENOFF, Stefann. Curso de Paragliding: básico e intermediário. [S.I: S.n.], 1998. Mimeografado.

SPINK, Mary Jane. Suor, Arranhões e Diamantes: as contradições dos riscos na modernidade reflexiva. Esterisco: estudo sobre tecnobiociências e risco na sociedade contemporânea. Disponível em: <http://www.ensp.fiocruz.br/projetos/ esterisco/suor1.htm>. Acesso em: 01/ jul/ 2008.

Movimento, Porto Alegre, v. 14, n. 03, p. 13-32, setembro/dezembro de 2008. 


\section{Artigos Orignais Giuliano Gomes de Assis Pimentel}

STIGGER, Marco Paulo. Esporte, lazer e estilos de vida: um estudo etnográfico. Campinas: Autores Associados, 2002.

TURNER, Victor W. O processo ritual: estrutura e antiestrutura. Petrópolis: Vozes, 1974. 